\title{
Impact of Selected Polyphenolics on the Structural Properties of Model Lipid Membranes - A Review
}

\author{
Nataša Poklar Ulrih ${ }^{a^{*}}$, Ajda Ota ${ }^{\mathrm{a}}$, And Veronika Abram ${ }^{\mathrm{a}}$ \\ ${ }^{a}$ Biotechnical Faculty, University of Ljubljana, SI-1000 Ljubljana, Slovenia \\ ${ }^{*}$ Corresponding author \\ natasa.poklar.ulrih@bf.uni-lj.si \\ TEL: $+386-1-3203780$
}

Received: 30 October 2016; Published online: 18 October 2017

Invited paper from the 4th International ISEKI Food Conference - ISEKI_Food 2016 - Bridging Training and Research for Industry and the Wider Community - Responsible Research and Innovation in the Food Value

\begin{abstract}
This review is a presentation of data gathered on the interactions of several polyphenolics (i.e., phenolic acids, stilbenes, flavonoids) with lipid bilayers of different lipid compositions. These polyphenolics have been investigated through a combination of fluorescence spectroscopy, electron paramagnetic resonance spectroscopy, and differential scanning calorimetry, to detect changes in membrane fluidity. Among the investigated phenolic acids, the least polar phenolic acid, $p$-coumaric acid, has the greatest effect on lipid membrane structure. It appears to have a greater ability to cross membranes by passive transport than more polar phenolic acids. On the other hand, among the flavonoids that have been studied, the anthocyanins cyanidin-3-glucoside and its aglycone are inactive. All of the flavonols tested, except for epigallocatechin-3-gallate, promote small decreases in membrane fluidity. Computer simulation of electron paramagnetic resonance spectra for flavonoids indicated two or three regions in the phosphatidylcholine/ phosphatidylserine (2.4:1) membrane with different fluidity characteristics. The effects of the different flavonoids are correlated to their structural characteristics, whereby even the difference in one - $\mathrm{OH}$ group can be important, as can the number of H-bonds they form. The role of membrane composition and flavonoid structure in these interactions with lipid membranes are of great importance for bioavailability of these compounds and for their biological effects in an organism.
\end{abstract}

Keywords: Phenolic acids; Flavonoids; Model lipid membrane; Interactions; Fluidity; Encapsulation

\section{Introduction}

Phenolic compounds or phenolics in herbs and spices have been thoroughly studied for several years to characterize, mainly in-vitro, their diverse biological effects. Among these are the phenolic acids, a diverse group of aromatic secondary plant metabolites that are widely distributed throughout the plant kingdom. Due to their almost universal distribution, phenolic acids are an integral part of the human diet (Laranjinha, 2001). Two classes of phenolic acids can be dis- tinguished: the hydroxybenzoic and hydroxycinnamic acids. Hydroxybenzoic acids (C6-C1) are rarely found in their free forms, except in processed food that has undergone freezing, sterilisation or fermentation (Manach, Scalbert, Morand, Remesy, \& Jimenez, 2004; Rosazza, Huang, Dostal, Volm, \& Rousseau, 1995). The hydroxycinnamic acids (C6-C3) include $p$-coumaric, caffeic and ferulic acids, and occur most frequently as simple esters. These have various biological and pharmacological activities, including antioxidative activities, which follow the sequence: caf- 
feic acid $>$ ferulic acid $>p$-coumaric acid (Cheng, Dai, Zhou, Yang, \& Liu, 2007). The free phenolic acids can be metabolised by different microorganisms, to produce their 4-vinyl derivatives, which can then be reduced to their 4-ethyl derivatives. Alternatively, hydroxycinnamic acids can be reduced to their substituted phenyl propionic acids, and then decarboxylated to generate their 4-ethyl derivatives (Barthelmebs, Divies, \& Cavin, 2000). The decarboxylated compounds are called styrenes.

Flavonoids (C6-C3-C6) are known to be synthesised by plants in response to microbial infections (Dixon, Dey, \& Lamb, 1983; Cowan, 1999). Therefore, it is not surprising that in-vitro they act as effective antimicrobials against a wide array of microorganisms. Flavonoids can interfere with the growth of microorganisms and they can act as synergists to increase the effects of preservatives. They can also modify the permeability of bacterial cell membranes, change the fatty-acid composition and phospholipid content of membranes, and interact with membrane proteins (Burt, 2004). The flavonoids are considered to be good antioxidants and cancer-suppressing agents (Surh, 2003).

Translocation of endogenous and exogenous compounds across cellular and intracellular membranes has a crucial role in determining their biological properties. This translocation across membranes is generally defined by the physicochemical properties of a compound; namely, its molecular weight, lipophilicity, electronic charge, and pKa, along with its hydrogen-bonding ability (Ziberna, Kim, Auger, Passamonti, \& SchiniKerth, 2013).

To obtain further insight into the mechanisms involved in the antioxidant and antimicrobial actions of selected phenolic acids and flavonoids work with model membranes has been done. The model membranes were set up as liposomes with one or more lipid bilayers and their interactions have been characterized using fluorescence spectroscopy, electron paramagnetic resonance (EPR) spectroscopy and differential scanning calorimetry (DSC); particularly of interest were encapsulated epigallocatechin-3-gallate (EGCG) and resveratrol.

\section{Chemical structures of investigated compounds}

The food industry is interested in phenolics particularly because they are good antioxidants and can therefore prevent oxidation processes and prolong the stability of foods, and also because they can act as antimicrobials. As part of the human diet, phenolics might also provide health benefits associated with reduced risk of chronic disease, potentially due to their reduction of oxidising agents, although the bioavailability of phenolics is reportedly very low in mammals (Ziberna et al., 2013) We have also shown that bilberry and blueberry anthocyanins can act as powerful intracellular antioxidants, even at very low concentrations $(<1 \mu \mathrm{g} / \mathrm{L}$; i.e. in the nanomolar range) (Bornsek et al., 2012). The fate of such phenolics in the human body is important to know when their in-vivo effects are considered, this is especially so because the transport of phenolics through cell membranes is still not well understood. We propose that the structure of a compound determines its behaviour in terms of its membrane transport, and that the polarity, number of H-bonds, and topological polar surface area (TPSA) can be used to predict how a phenolic acid or flavonoid will penetrate cell membranes (i.e., by passive transport or transporter proteins). Figure 1 shows the structural formulae of the phenolics considered here.

\section{Interactions of phenolics with liposomes, as model lipid membranes}

The main routes by which phenolics and their metabolites can cross cell membranes are active and passive transport. There is growing evidence that in-vivo, phenolics are transported through cell membranes via transporters with only marginal contributions from non-specific passive diffusion. In support of this, over $10 \%$ of all functionally characterised genes encode for transporters or transport-related proteins, of which some 1,300 to 1,500 have already been identified (Ziberna et al., 2013). On the other hand, the interactions of phenolics with the lipid and protein membrane components might 
Polyphenolics and model lipid membranes $\mid 161$

p-Coumaric acid<smiles>O=C(O)/C=C/c1ccc(O)cc1</smiles>

Resveratrol<smiles>Oc1ccc(/C=C/c2cc(O)cc(O)c2)cc1</smiles>

Caffeic acid<smiles>O=C(O)/C=C/c1ccc(O)c(O)c1</smiles>

Ferulic acid<smiles>COc1cc(/C=C/C(=O)O)ccc1O</smiles>

Styrene<smiles>C=Cc1ccccc1</smiles>

(+)-Catechin<smiles>Oc1cc(O)c2c(c1)OC(c1ccc(O)c(O)c1)C(O)C2</smiles>

(-)-Epicatechin<smiles>Oc1cc(O)c2c(c1)OC(c1ccc(O)c(O)c1)C(O)C2</smiles>

(-)-Epigallocatechin (EGC)<smiles>Oc1cc(O)c2c(c1)OC(c1cc(O)c(O)c(O)c1)C(O)C2</smiles>

(-)-Epigallocatechin-3-gallate (EGCG)<smiles>O=C(O)C1Cc2c(O)cc(O)cc2OC1c1ccc(O)c(O)c1</smiles>

Butylated hydroxytoluene (BHT)<smiles>Cc1cc(C(C)(C)C)c(O)c(C(C)(C)C)c1</smiles>

Figure 1: Structural formulae of three hydroxycinnamic acids, the stilbene resveratrol, styrene, four flavonoids, and a synthetic antioxidant, butylated hydroxytoluene. 
be partially responsible for phenolics actions on human and animal health (Verstraeten, Fraga, \& Oteiza, 2015). Such interactions might thus affect membrane-associated processes like regulation of enzymes, channels and receptors and membrane-initiated cell signalling (Fraga \& Oteiza, 2011; Selvaraj, Krishnaswamy, Devashya, Sethuraman, \& Krishnan, 2015).

Liposomes are artificial spherical vesicles that are composed of one or more lipid bilayers that surround an aqueous core (Fig. 2A and 2B). They are defined according to the number of bilayers, as multilamellar vesicles (MLVs), which are heterogeneous in size with diameters of 100 $\mathrm{nm}$ to $4,000 \mathrm{~nm}$, and unilamellar vesicles (ULVs), with diameters of $20 \mathrm{~nm}$ to $30 \mathrm{~nm}$ for small ULVs and $40 \mathrm{~nm}$ to $1,000 \mathrm{~nm}$ for large ULVs. ULVs are predominantly prepared by extrusion of MLVs through filters with well-defined pores. The diameter of the resultant ULVs depends on the diameter of the pores, although in general ULVs are not smaller than $60 \mathrm{~nm}$ (Lasic, 1993). The liposomes presented here were prepared in this way as MLVs and ULVs.

Liposomes are commonly formed from naturally occurring compounds, and their application to food systems as new formulations should be easy to implement. Briefly here, each phospholipid is dissolved in chloroform:methanol solution $(7: 3, \mathrm{v} / \mathrm{v})$, with a certain volume transferred to a rotary flask. The solvents are completely evaporated off under reduced pressure (17 mbar), which provides a thin phospholipid film in the flask. These lipid films are hydrated by the addition of water, with the mixture shaken for $2 \mathrm{~h}$ while maintaining a temperature above that of the phase transition of the phospholipids in the liposome preparation; i.e., at 40 ${ }^{\circ} \mathrm{C}$ for the formation of phosphatidylcholine/ phosphatidylserine (PC/PS) liposomes, and above $45{ }^{\circ} \mathrm{C}$ for 1,2-dipalmitoyl-sn-glycero-3phosphocholine (DPPC) liposomes (Fig. 2C) (Šentjurc, Vrhovnik, \& Kristl, 1999). When a phenolic compound needs to be added to liposomes, each one is dissolved in the same mixture of organic solvents and added to the phospholipids before preparation of the thin lipid film. For fluorescence measurements, aliquots of flavonoids were added to liposome suspensions.
Membrane fluidity was measured in our studies with MLVs and ULVs that consisted of 1-palmitoyl-2-oleoyl-sn-glycero3-phosphocholine (POPC), 1-palmitoyl-2oleoyl-sn-glycero-3-phosphoethanolamine

(POPE), 1-palmitoyl-2-oleoyl-sn-glycero-3phospho-L-serine (POPS) and cholesterol (i.e., $\mathrm{POPC} / \mathrm{POPE} / \mathrm{POPS} /$ cholesterol) in the molar ratio of 4:2:1:3.6, or of $\mathrm{PC}$ (from egg), and sphingomyelin (SM; from egg) at the molar ratio of 2.4:1. The former lipid composition was selected to represent a model membrane, as suggested by Kier (1990), and the latter one to determine changes in the absence of cholesterol. Fluorescence polarisation provides information about the mobility of the molecular orientation and processes that modulate this, and it is inversely correlated to membrane fluidity. These liposomes were in the liquid-disordered form at $25{ }^{\circ} \mathrm{C}$. DSC is a fundamental technique for characterisation of membrane behaviour after the temperature-induced transitions that can be caused by added components. The DSC method measures the changes in the enthalpy, $\Delta H$, and the phase transition temperature $\left(T_{m}\right)$, of the liposome lipids from the gel to the liquid crystalline state, while the fluorescence polarisation and EPR spectroscopy are more sensitive to the dynamics of the molecules within a certain range of probes. The energy changes, using DSC, were investigated with ULVs made with DPPC. DPPC is a saturated glycerophospholipid that is one of the most abundant lipids in cell membranes, and it is suitable for monitoring of gel-to-liquid phase transitions. Figure 3 illustrates schematically the phase transitions of liposomes composed of saturated lipids (e.g., DPPC) when unsaturated lipids are introduced.

\subsection{Phenolic acids}

\section{Energy changes for DPPC gel-to-liquid phase transition caused by phenolic acids and their styrenes}

DSC was used to determine the energy changes caused by selected phenolic acids and their styrenes as a result of incorporation into lipid 
Polyphenolics and model lipid membranes | 163

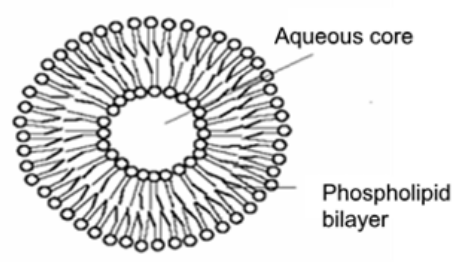

A

C

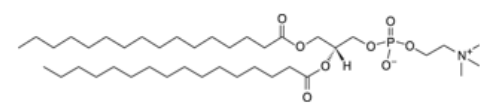

DPPC

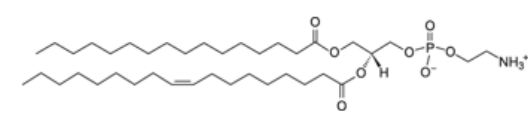

POPE

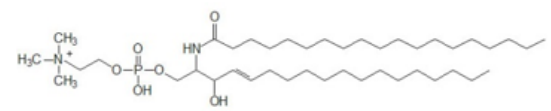

Sphingomyelin

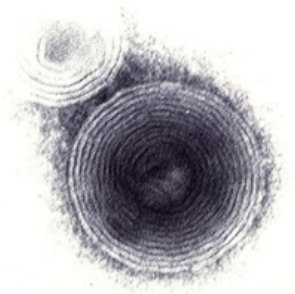

B
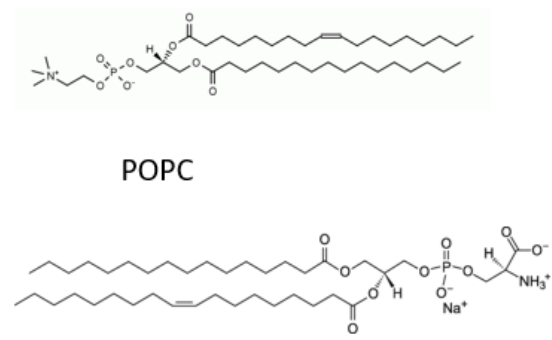

POPS

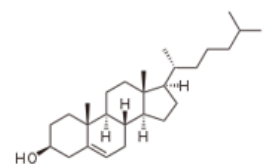

Cholesterol

Figure 2: (A) Schematic liposome composed of one phospholipid (modified from https://en.wikipedia. org/wiki/Liposome). (B) Microscopic image of liposome composed of several bilayers surrounding an aqueous core, in water solution. (C) Structural formulae of the lipids used for the liposome preparations considered here. DPPC, 1,2-dipalmitoyl-sn-glycero-3-phosphocholine; POPC, 1-palmitoyl-2-oleoylsn-glicero-3-phosphocholine; POPE, 1-palmitoyl-2-oleoyl-sn-glicero-3-phosphoethanolamine; POPS, 1palmitoyl-2-oleoyl-sn-glicero-3-phospho-L-serine. 
$164 \mid$ Ulrih et al.

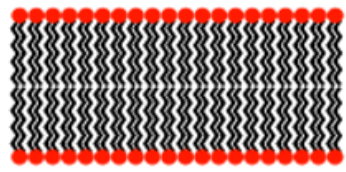

Saturated lipids only

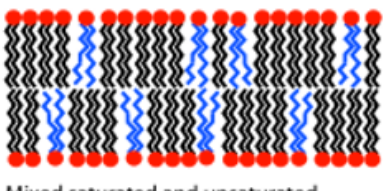

Mixed saturated and unsaturated

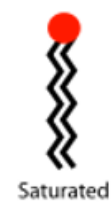

Saturated

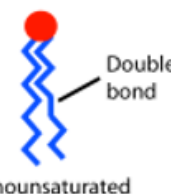

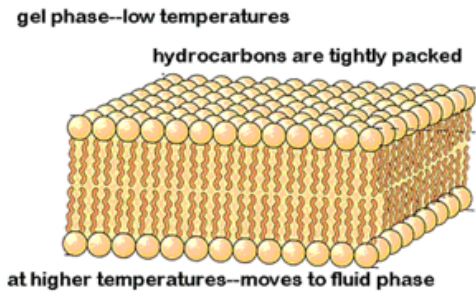

at higher temperatures--moves to fluid phase

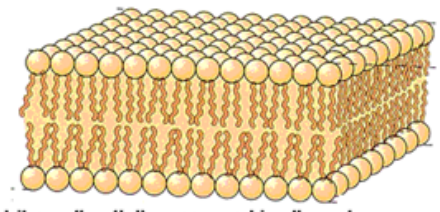

bilayer "melts", movement is allowed

Figure 3: Schematic representation of phase transitions of lipids, according to differential scanning calorimetry. (modified from http://en.wikipedia.org/wiki/Lipid_bilayer_phase_behavior)

bilayers of ULVs prepared from DPPC (Table 1). The lipid thermotropic phase behaviour was followed in the presence of a 1:1 molar ratio of the compounds studied (versus DPPC), in the temperature range from $10{ }^{\circ} \mathrm{C}$ to $70{ }^{\circ} \mathrm{C}$. At molar ratios lower than 1:1, the effect of phenolic acids and their styrenes on the phase transition of lipids was not large enough so we have decided to perform the DSC experiments at higher molar ratios. The main phase transition temperature for the lipid - $T_{m}$ which is known as the gel-to-liquid phase transition, generally gives rise to a very intense and sharp peak in the heat capacity. Conversely, the pre-transition temperature $\left(T_{m}^{\prime}\right)$ is usually detected as a much less intense and broader peak at lower temperatures (Riske et al., 2009). Figure 4 shows the DSC profiles of DPPC ULVs in the absence and presence of $p$-coumaric, caffeic and ferulic acids (Ota, Abramovic, Abram, \& Ulrih, 2011).

These data demonstrate that the selected phenolic acids cause decreases in $T^{\prime}{ }_{m}$ and $T_{m}$, and that the least polar of these phenolic acids (i.e., $p$-coumaric) had the greatest effects on the structure of the membrane lipids (i.e., destabilising of the structure; see Fig. 3). The enthalpy of the main transition of the DPPC decreased in the presence of $p$-coumaric acid by $1.46 \pm 0.10$ $\mathrm{kcal} / \mathrm{mol}$ (Ota et al., 2011). Caffeic acid and fer- ulic acid are both more polar than $p$-coumaric acid (see Fig. 1), and they had smaller effects on the rigidity and dynamics of the DPPC chains. The respective styrenes also significantly decreased both $T^{\prime}{ }_{m}$ and $T_{m}$, as well as the corresponding enthalpies (Ota et al., 2011).

\section{Effects of hydroxycinnamic acids on model lipid membranes in the liquid state}

The polarisation values of MLVs and ULVs composed of POPC/POPE/POPS/cholesterol (4:2:1:3.6) before addition of the phenolic acids and their styrenes were $0.2410 \pm 0.0006$ and $0.3200 \pm 0.0005$, respectively. Once the lipids are in the liquid form, as here, the gel-to-liquid transition cannot be followed using DSC. Therefore, steady-state polarisation measurements with the non-polar fluorophore 1,6-diphenyl-hexa-1,3,5triene (DPH) were performed at $25^{\circ} \mathrm{C}$ to compare the effects at the same level of the order as the lipid mixtures tested. It is known that anisotropy and polarisation are highest in the gel state, lowest in the liquid-disordered state, and intermediate in the liquid-ordered state $(\mathrm{Xu} \&$ London, 2000). Based on these polarisation measurements defined with DPH, we can conclude that the lipid bilayer of the ULVs was more or- 


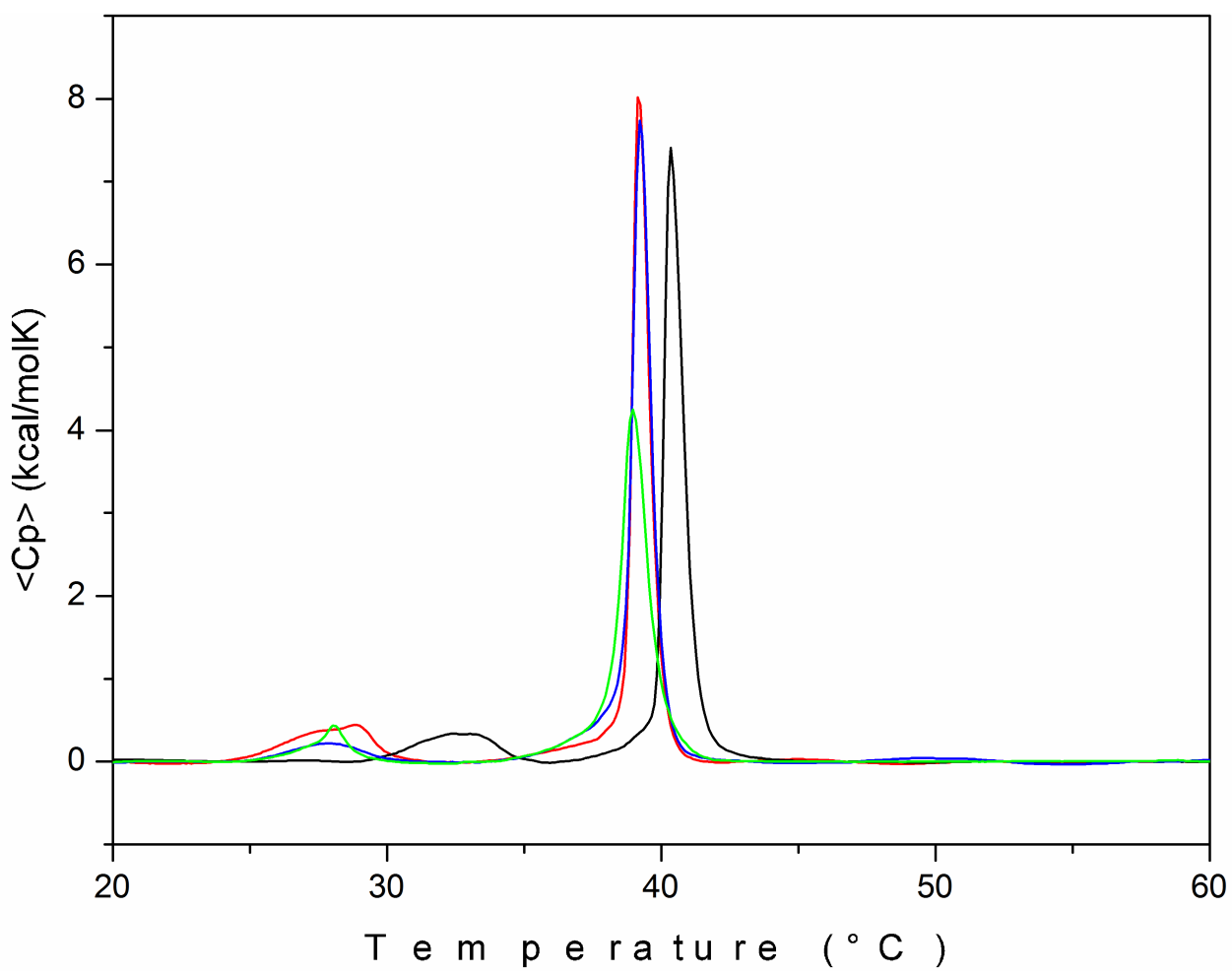

Figure 4: Differential scanning calorimetry profiles of DPPC ULVs in the absence (black) and presence of the $p$-coumaric (green), caffeic (blue) and ferulic (red) acids (from Ota, Abramovic, Abram, and Ulrih (2011).

dered compared to that of the MLVs, which are more heterogeneous in terms of their polydispersion index (Mui \& Hope, 2006).

The addition of $p$-coumaric, caffeic and ferulic acids caused increases in both the anisotropy and polarisation of DPH in the presence of the MLVs and ULVs (measured as changes in polarisation; $\Delta \mathrm{P}$ ) if the lipids are in the liquiddisordered state. The highest effect on the polarisation was determined to be that caused by $p$-coumaric followed by ferulic and caffeic acid. Such changes in polarisation were correlated to the polarity of the compound and the lipid membrane fluidity. The phenolic acids increased the order and decreased the dynamics of the phospholipid alkyl chains of these model lipid membranes, while the styrenes had the opposite effects (see Fig. 5). With the styrenes at molar ratios $>1$ (i.e., $\mathrm{R}=\mathrm{n}_{\text {ligand }} / \mathrm{n}_{\text {lipid }}$ and a styrene as a ligand), the membranes become more fluid.
These data suggest that at lower molar ratios of phenolic acids to lipids there are ordering effects on the lipid membranes, while the effects of the styrenes are the opposite. This behaviour can be explained by the polarities of these phenolic acids and their styrenes (Table 2), and thus to what level they can penetrate into the lipid bilayer (Ota et al., 2011).

\section{Effects of hydroxycinnamic acids on model lipid membranes in the gel state}

The ULVs made from DPPC were in the gel state. Addition of $p$-coumaric acid to these ULVs caused decreased polarisation of DPH, while addition of caffeic and ferulic acids had no significant effects. Based on these data, it can be concluded that the hydroxycinnamic acids, which are negatively charged, cannot cross the lipid

\begin{tabular}{l|l|l|l} 
IJFS & October 2017 & Volume 6 & pages 159-177
\end{tabular} 
Table 1: Thermodynamic profiles of the DPPC lipids as ULVs, at $\mathrm{pH} 7.0$, and in the presence of the phenolic acids and their styrenes (adapted from Ota, Abramovic, Abram, and Ulrih (2011)) and of selected flavonoids and a synthetic antioxidant BHT at a molar ratio of 1:1 (adapted from Abram et al. (2013))

\begin{tabular}{|c|c|c|c|c|}
\hline Sample & $\begin{array}{l}\boldsymbol{T}_{m}^{\prime} \\
\left({ }^{\circ} \mathrm{C}\right)\end{array}$ & $\begin{array}{c}\boldsymbol{T}_{m} \\
\left({ }^{\circ} \mathbf{C}\right)\end{array}$ & $\begin{array}{c}\Delta \boldsymbol{H}_{\text {pre }} \\
\text { (kcal/mol) }\end{array}$ & $\begin{array}{c}\Delta \boldsymbol{H}_{c a l} \\
\text { (kcal/mol) }\end{array}$ \\
\hline $\mathrm{DPPC}(\mathrm{c}=0.5 \mathrm{mg} / \mathrm{mL})$ & $32.6 \pm 0.2$ & $40.4 \pm 0.1$ & $1.34 \pm 0.19$ & $8.39 \pm 0.10$ \\
\hline $\mathrm{DPPC}(\mathrm{c}=10.0 \mathrm{mg} / \mathrm{mL})$ & $31.5 \pm 0.1$ & $39.7 \pm 0.1$ & $3.7 \pm 0.05$ & $32.3 \pm 0.50$ \\
\hline DPPC : 4-vinylphenol & $28.1 \pm 0.2$ & $37.9 \pm 0.1$ & / & $5.71 \pm 0.05$ \\
\hline DPPC : 4-vinylcatechol & $28.8 \pm 0.2$ & $37.4 \pm 0.1$ & $0.19 \pm 0.01$ & $7.50 \pm 0.05$ \\
\hline DPPC : 4-vinylguaiacol & $28.7 \pm 0.2$ & $36.6 \pm 0.1$ & $0.19 \pm 0.05$ & $7.74 \pm 0.10$ \\
\hline DPPC : $p$-coumaric acid & $28.0 \pm 0.2$ & $39.0 \pm 0.1$ & $0.74 \pm 0.02$ & $6.93 \pm 0.02$ \\
\hline DPPC : caffeic acid & $27.8 \pm 0.2$ & $39.3 \pm 0.1$ & $0.79 \pm 0.10$ & $8.25 \pm 0.05$ \\
\hline DPPC : ferulic acid & $28.4 \pm 0.2$ & $39.2 \pm 0.1$ & $1.39 \pm 0.14$ & $7.93 \pm 0.07$ \\
\hline DPPC: catechin & $31.9 \pm 0.1$ & $39.6 \pm 0.1$ & $5.3 \pm 0.5$ & $32.7 \pm 0.50$ \\
\hline DPPC: epicatechin & $31.5 \pm 0.1$ & $\begin{array}{c}39.6 \pm 0.1 \\
39.2 \pm 0.1\end{array}$ & $3.1 \pm 0.5$ & $33.1 \pm 0.50$ \\
\hline DPPC: EGC & $31.7 \pm 0.1$ & $\begin{array}{l}39.7 \pm 0.1 \\
39.3 \pm 0.1\end{array}$ & $3.2 \pm 0.5$ & $32.2 \pm 0.5$ \\
\hline DPPC: EGCG & $31.7 \pm 0.1$ & $\begin{array}{l}39.8 \pm 0.1 \\
37.6 \pm 0.1\end{array}$ & $0.6 \pm 0.5$ & $\begin{array}{l}12.6 \pm 0.5 \\
10.5 \pm 0.5\end{array}$ \\
\hline DPPC: BHT (1:1) & & & $33.0 \pm 0.1$ & $30.9 \pm 0.5$ \\
\hline
\end{tabular}

$T^{\prime} m$, pretransition phase temperature; $T_{m}$, gel-to-liquid crystalline phase transition temperature; $\Delta H^{\prime}{ }_{c a l}$, enthalpy of pretransition; $\Delta H_{\text {cal }}$, enthalpy of gel-to-liquid crystalline transition. DPPC, 1,2-dipalmitoyl-sn-glycero-3-phosphocholine; EGC, epigallocatechin; EGCG, epigallocatechin-3-gallate; BHT, butylated hydroxytoluene

bilayer of the zwitterionic DPPC lipids in the gel state. Indeed, the hydroxycinnamic acids have little effect on the structure and energy of these DPPC lipid membranes. The greatest effects on the stability of the lipid membranes were seen for $p$-coumaric acid, which suggests that the aromatic ring of this phenolic acid is likely to be partially inserted into this lipid bilayer. On the other hand, the styrenes caused decrease in the anisotropy and polarisation of DPH, which suggests that they can penetrate into the DPPC lipid bilayer and cause decreased order and increased dynamics of the phospholipid alkyl chains in this gel form, similar to what was seen for the model lipid membranes in the liquid form. These interactions of the hydroxycinnamic acids and their styrenes with the membranes can also be explained according to their polarities (Table 2 ). Here, $p$-coumaric acid had the highest destabilisation effect on the enthalpy and the temperature of the gel-to-liquid transition of DPPC, and on the polarisation, due to its lowest TPSA and higher $\log$ P. Caffeic acid has the highest polar surface area among these hydroxycinnamic acids, as it has two $-\mathrm{OH}$ groups in the $o$-position. Caffeic acid can form seven $\mathrm{H}$-bonds, with three as an H-bond donor, and four as an H-bond acceptor. Indeed, its partition coefficient was the lowest of these phenolic acids, and it was the least soluble in octanol. The effects of caffeic acid on the polarisation were almost the same as those of ferulic acid. Here, the destabilisation effects followed the order: $p$-coumaric acid $>$ caffeic acid $\geq$ ferulic acid. The differences between $p$-coumaric (the least polar among these hydroxycinnamic acids) and caffeic acid (the most polar) was for TPSA, at $26 \%$, and $\log P$, at $25 \%$. The differences in structure between these two hydroxycinnamic acids are clearly reflected in the $\Delta \mathrm{P}$ : ferulic acid has an $-\mathrm{OCH}_{3}$ group instead of an $-\mathrm{OH}$ group, and so it can influence the ordering of the lipid bilayers the least. It is interesting to note that the antioxidant efficacies of these hydroxycinnamic acids determined in-vitro followed the 


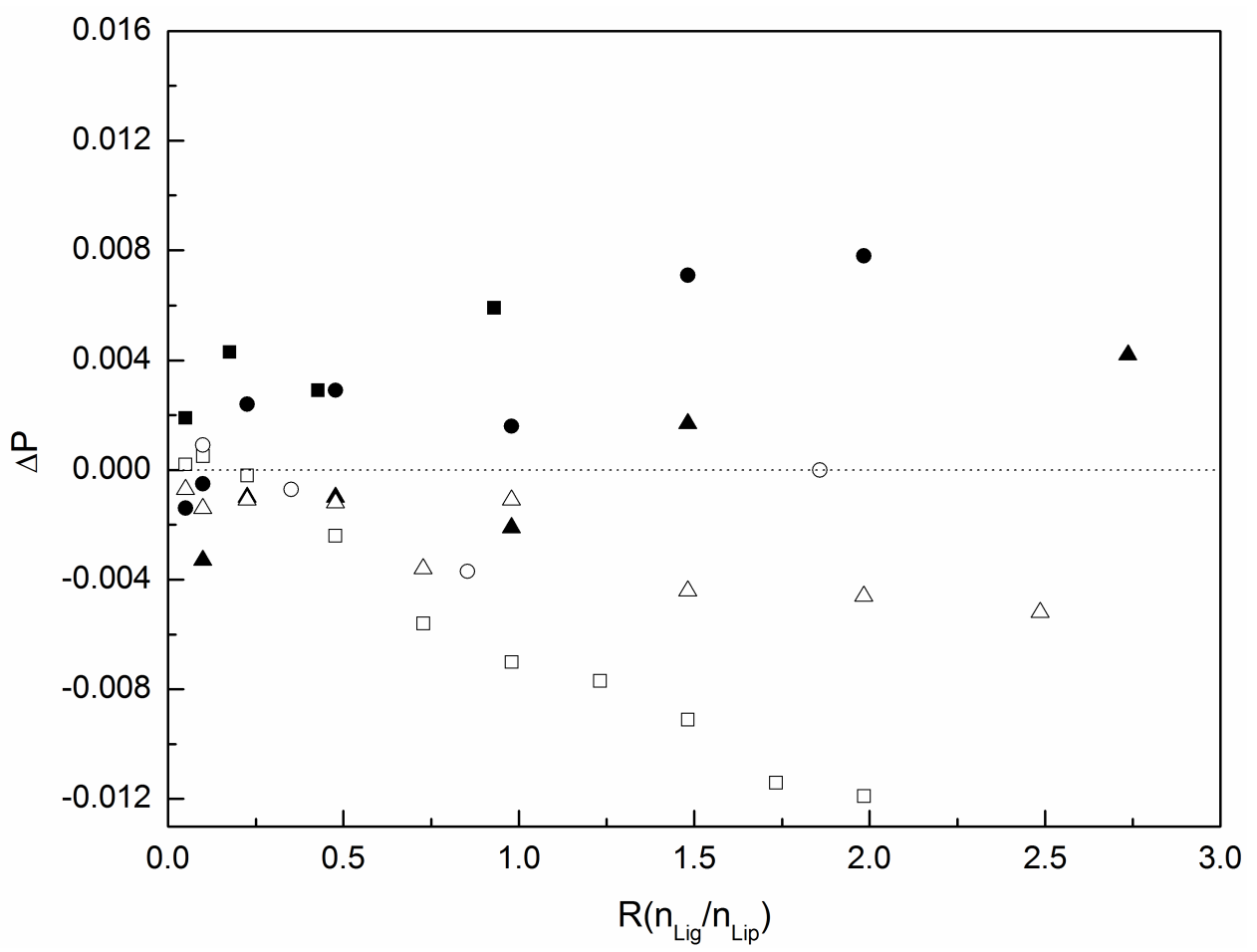

Figure 5: Changes in polarisation $(\Delta \mathrm{P})$ of the fluorophore 1,6-diphenyl-hexa-1,3,5-triene in POPC/POPE/POPS/cholesterol ULVs (see text for details). The polarisation of these ULVs before addition of the phenolic acids and their styrenes was 0.3200 \pm 0.0005 (Ota, Abramovic, Abram, \& Ulrih, 2011). Data are shown for the addition of $p$-coumaric $(\boldsymbol{\square})$, caffeic $(\boldsymbol{\Delta})$ and ferulic $(\bullet)$ acids, and their styrenes 4-vinylphenol $(\square)$, 4-vinylcatechol $(\triangle)$ and 4-vinylguaiacol (o).

opposite order: caffeic acid $>$ ferulic acid $>p$ coumaric acid (Kadoma \& Fujisawa, 2008; Gumul \& Korus, 2006).

\subsection{Flavonoids}

\section{Effects of flavonoids on membrane fluidity}

Multilamellar vesicles and ULVs of POPC/POPE/POPS/cholesterol in the molar ratio of $4: 2: 1: 3.6$ are in the liquid-disordered form at $25{ }^{\circ} \mathrm{C}$. With these liposomes, at molar ratios $>0.1$ (i.e., $\mathrm{R}=\mathrm{n}_{\text {ligand }} / \mathrm{n}_{\text {lipid }}$ and a flavonoid as a ligand), increased polarisation with kaempferol and epigallocatechin (EGC) was seen, but not with EGC-3-gallate (EGCG). This behaviour has been attributed to the structure of these flavonoids (Fig. 1). The changes in polarisation of the MLVs and ULVs correlated with the hydrophobicities of these compounds, because the hydrophobicity depends on the dipole moment, dielectric constant, and number of H-bonds, and hence their miscibility with water (Table 2). We have shown that the hydrophobicity of these tested flavonoids reflects well on the behaviour here, with the same order for the increase in polarisation obtained: $\mathrm{K}>$ EGC > KG > EGCG (Ulrih, Ota, Sentjurc, Kure, \& Abram, 2010).

As each cell membrane has a different selectivity that depends on its composition, and thus modulates the passage of substances into the cell (Šentjurc, Štrancar, \& Koklič, 2002), we investigated how an absence of cholesterol would affect the interactions of the same catechol-type 
$168 \mid$ Ulrih et al.

Table 2: Topological polar surface area (TPSA), number of H-bonds and partition coefficients $(\log P)$ for octanol water mixtures for phenolic acids and their styrenes, selected flavonoids, and the synthetic antioxidant butylated hydroxytoluene (PubChem, 2010, 2017)

\begin{tabular}{lccc}
\hline Phenolic compound & TPSA & H-bonds & Log $\boldsymbol{P}$ \\
\hline 4-vinylcatechol & - & - & - \\
4-vinylphenol & 20.2 & 2 & 2.4 \\
4-vinylguaiacol & 29.5 & 3 & 2.4 \\
p-coumaric acid & 57.5 & 5 & 1.5 \\
Ferulic acid & 66.8 & 6 & 1.5 \\
Caffeic acid & 77.8 & 7 & 1.2 \\
(+)-Catechin & 110 & 11 & 0.4 \\
(-)-Epicatechin & 110 & 11 & 0.4 \\
(-)-Epigallocatechin & 131 & 13 & 0 \\
(-)-Epigallocatechin-3-gallate & 197 & 19 & 1.2 \\
Butylated hydroxytoluene & 20.2 & 2 & 5.3 \\
\hline
\end{tabular}

flavonoids and their derivatives with model lipid membranes. All of the selected compounds have powerful antioxidant activities (Terao, 2009). Therefore, we investigated how the structural properties (i.e., partition coefficient, number of H-bonds, TPSA) of (+)-catechin, (-)-epicatechin, (-)-EGC, and (-)-EGCG (see Fig. 1) correlate with the structural changes in model lipid membranes prepared from $\mathrm{PC}$ and SM (PC/SM; 2.4:1) or from DPPC alone. For comparison, the synthetic antioxidant butylated hydroxytoluene (Fig. 1, BHT) was included, which is a lipophilic compound that is used as an additive in foods, cosmetics and pharmaceuticals (i.e., E321).

Changes in the fluorescence polarisation of the two fluorophores DPH and N,N,N-trimethyl-4(6-phenyl-1,3,5-hexatrien-1-yl)phenylammonium $p$-toluenesulfonate (TMA-DPH) were measured to provide insight into the ordering parameters of the PC/SM (2.4:1) lipid bilayers. As indicated above, DPH is a non-polar fluorophore, and it can be used to monitor changes in the middle of the membrane bilayer. Conversely, TMA-DPH is an amphiphilic compound that can be used to probe membrane properties more towards the lipid head-group region of the membranes (Lakowicz, 2006). The data for the effects of catechin, epicatechin, EGC, EGCG on the fluorescence polarisation are shown in Fig. 6 and of cyanidin and cyanidin-3-O-glucoside in Table 3. The effect of flavonoids on fluorescence polarisation was more pronounced in the upper part of the membrane as measured with TMADPH (Fig. 6C and 6D) than in the membrane interior (Fig. 6A and 6B). The most pronounced increase in fluorescence polarisation with respect to the control was observed for EGCG with both fluorophores. The changes caused by EGC, epicatechin and catechin measured with DPH in the inner part of the membrane were about the same (Figs. 6A, 6B), while in the upper part of the membrane the less pronounced changes were observed with catechin (Fig. 6C and 6D). The measured flavonoids in PC:SM liposomes thus increase order and decrease the dynamics of the acyl chains of phospholipids in the vicinity of DPH or TMA-DPH. Contrary to the flavonoids, BHT decreases fluorescence polarisation pronouncedly, thus having disordering effect on the lipids in the membrane interior as measured by DPH (Abram et al., 2013). From Table 3 it can be concluded that changes in the fluorescence polarisation of an anthocyanidin were very small and the membrane properties were not changed. This means that neither cyanidin nor cyanidin-3-glucoside can pass the membrane by passive diffusion (Bornsek et al., 2012).

With EPR spectroscopy, the temperature dependence of the empirical correlation time 
$(\tau)$ was investigated with two spin probes, $\operatorname{MeFASL}(10,3)$ and $\operatorname{MeFASL}(2,11)$. With $\tau$ calculated from the EPR spectra, it gives a rough estimation of the ordering and dynamics of the spin probe motion. The spin probe used reflects the motion of the surrounding lipids, and thus the changes caused by the incorporation of a compound into such ULV membranes. With respect to the positions of the nitroxide group in $\operatorname{MeFASL}(10,3)$ and $\operatorname{MeFASL}(2,11)$, MeFASL $(10,3)$ reports on the membrane fluidity characteristics close to the water-lipid interface, while MeFASL $(2,11)$ reports on them in the middle of the bilayer (Subczynski, Wisniewska, Yin, Hyde, \& Kusumi, 1994). Figure 7 shows that with increasing temperature, $\tau$ decreased for both of these spin probes, thus reflecting the pronounced fluidity increase arising from the temperature increase. At the same time, all of the flavonoids investigated increased $\tau$ with respect to the control; i.e., they decreased the membrane fluidity in the outer part of the membrane as well as deeper in the membrane. The most pronounced changes were observed with EGCG in the PC/SM liposomes, as seen also for the fluorescence polarisation measurements. However, the changes produced with the other flavonoids were different (Abram et al., 2013). The EPR spectroscopy data measured directly from the spectra provide information about the average fluidity characteristics of the membranes in the vicinity of the probe, although without taking into account that the membrane can be composed heterogeneously of regions with different fluidity characteristics (e.g., the inner and outer leaflets of the membrane, close to the polar head groups, in the middle of the membrane, and lateral membrane heterogeneity). Therefore, for a more precise description of the membrane characteristics, computer simulation of the EPR spectra is necessary. This takes into account that an experimental EPR spectrum is a superposition of several spectral components with sets of parameters that reflect the spin probe motion in regions with different fluidity characteristics (Strancar, Koklic, \& Arsov, 2003, 2005). For the control samples, for the outer part of the membrane monitored by $\operatorname{MeFASL}(10,3)$, and with two spectral components with different motional modes used, a good fit with the exper- imental spectra was obtained (Fig. 8). Figure 8 shows the temperature dependence of the order parameters of these two spectral components. Here, the diameters of the circles represent the proportions of the spin probe in the membrane region with the corresponding order parameter. With increased temperature, the proportion of the more ordered component and the order parameter decreases. With the addition of the flavonoids, the order parameter is slightly higher for epicatechin and EGC than for control. With EGCG, there is an additional component that appears to show a significantly higher order parameter, and this thus indicates that the addition of EGCG increases the membrane heterogeneity. Conversely, with the addition of BHT, there is an additional component with a lower order parameter at temperatures below $25{ }^{\circ} \mathrm{C}$. At the higher temperatures, the order parameter decreases as a consequence of increased fluidity. The other parameters that were defined by the computer simulation did not change significantly after addition of these flavonoids.

DSC was used to monitor the changes in the thermotropic properties of the liposome membranes influenced by the incorporation of the investigated compounds (Fig. 9).

Epigallocatechin-3-gallate had the greatest effects on the membrane structure, although it interacts primarily with the liposome membrane surface (Table 1), and cannot cross the membrane by passive diffusion. Based on this, it can be concluded that the $-\mathrm{OH}$ group on the $\mathrm{C} 3$ moiety is more important than the 5,7-dihydroxy on the A-ring and the 3', 4'-dihydroxy on the B-ring (Abram et al., 2013).

\section{Encapsulation of epigallocatechin-3-gallate}

Green tea contains substantial amounts of flavan3-ols (C6-C3-C6), as mainly (-)-EGC, (+)gallocatechin, (-)-epicatechin-3-O-gallate and (-)-EGCG. The levels of these monomers decline markedly during fermentation of tea leaves, and the main components in black tea are theaflavin gallates and more substantial quantities of the high molecular weight thearubigins (RodriguezMateos et al., 2014). EGCG is the most active 
$170 \mid$ Ulrih et al.
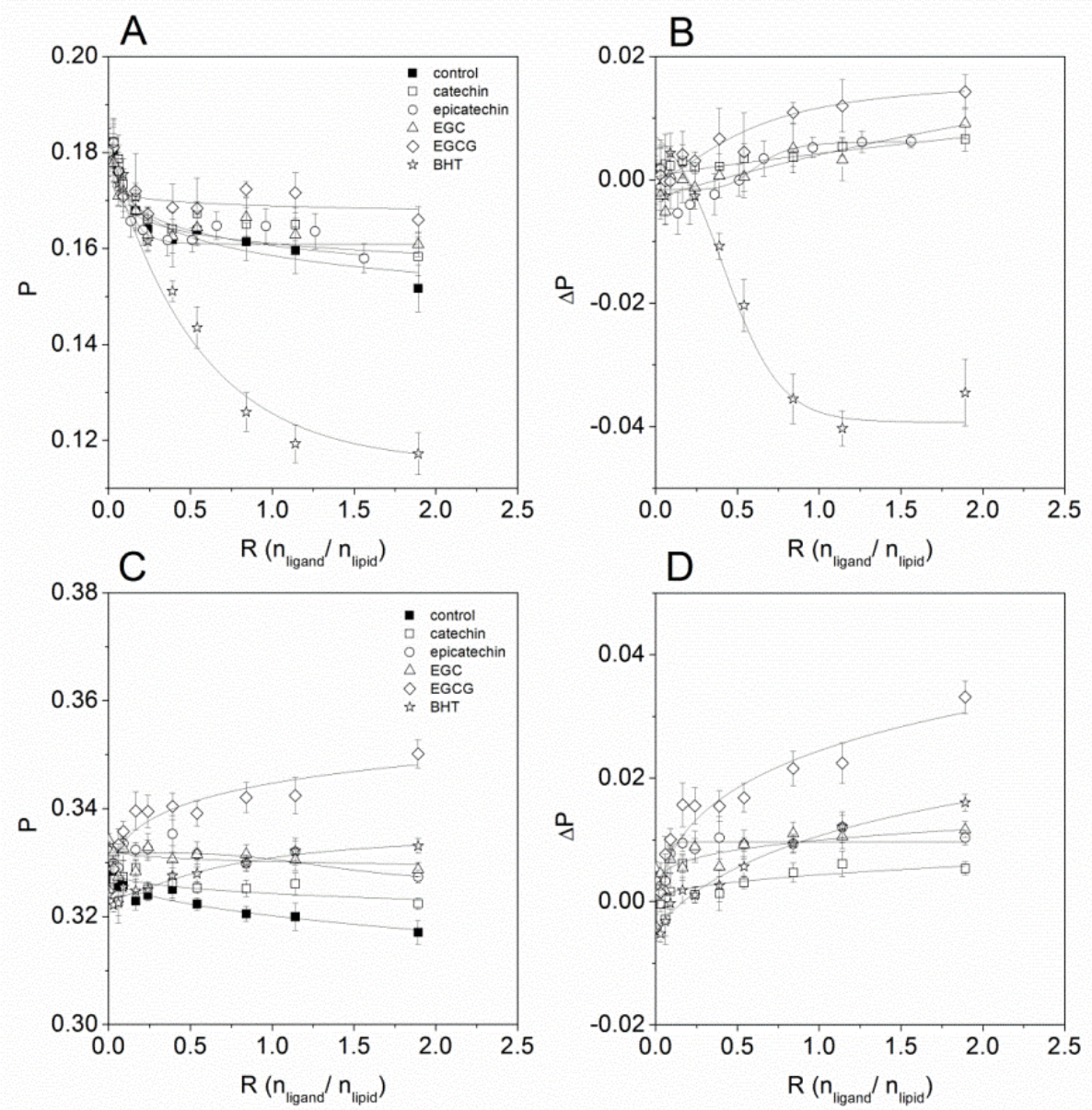

Figure 6: Fluorescent polarisation, $P$, of the DPH (A) and TMA-DPH (C) fluorophores, expressed also as the changes seen, $\Delta \mathrm{P}$ (with ethanol effects on $\mathrm{DPH}$ polarisation subtracted) ( $\mathrm{B}, \mathrm{D}$, respectively), for ULVs (PC:SM, 2.4:1) in the presence of different molar ratios ( $\mathrm{R}$ : $\mathrm{n}_{\text {ligand }}$ to $\mathrm{n}_{\text {lipid }}$ ) of catechin, epicatechin, epigallocatechin (EGC), epigallocatechin-3-gallate (EGCG), and butylated hydroxytoluene (BHT), at $25^{\circ} \mathrm{C}$. The standard deviations of two independent measurements were $<5 \%$ (Abram et al., 2013). 
Polyphenolics and model lipid membranes $\mid 171$

Table 3: Fluorescence polarisation of a fluorophore DPH, expressed as changes $\Delta \mathrm{P}$, against the same concentration of cyanidin and cyanidin-3-glucoside in ULVs (PC/SM, 2.4:1). Three replicates were performed and mean \pm sd of $\Delta \mathrm{P}$ calculated

\begin{tabular}{ccc}
\hline $\begin{array}{c}\text { Concentration, } \\
(\mu \mathbf{g} / \mathbf{L})\end{array}$ & $\begin{array}{c}\Delta \mathbf{P} \text { of Cyanidin } \\
\text { (mean } \pm \mathbf{~ s d )}\end{array}$ & $\begin{array}{c}\Delta \mathbf{P} \text { of Cyanidin-3-glucoside } \\
\text { (mean } \pm \mathbf{~ s d )}\end{array}$ \\
\hline 0 & $-0.0020 \pm 0.0009$ & $-0.0009 \pm 0.0002$ \\
0.25 & $0.0004 \pm 0.0006$ & $0.0012 \pm 0.0010$ \\
0.50 & $0.0011 \pm 0.0010$ & $0.0023 \pm 0.0008$ \\
1.00 & $-0.0009 \pm 0.0020$ & $0.0000 \pm 0.0011$ \\
2.00 & $-0.0001 \pm 0.0018$ & $0.0001 \pm 0.0001$ \\
5.00 & $0.0012 \pm 0.0014$ & $0.0010 \pm 0.0010$ \\
10.00 & $0.0020 \pm 0.0019$ & $0.0029 \pm 0.0005$ \\
25.00 & $0.0006 \pm 0.0018$ & $0.0033 \pm 0.0012$ \\
50.00 & $0.0007 \pm 0.0009$ & $-0.0007 \pm 0.0006$ \\
\hline
\end{tabular}
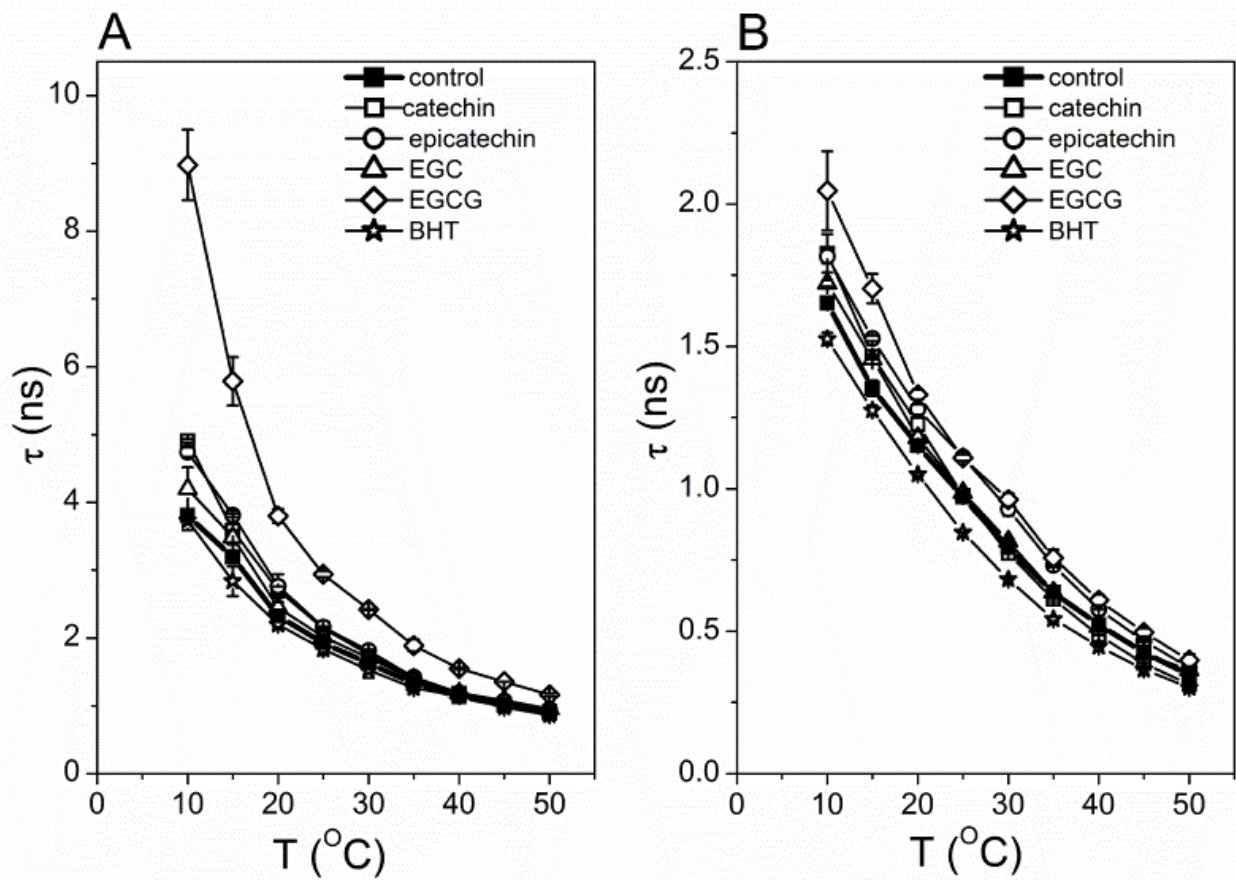

Figure 7: Temperature dependence of the empirical correlation time $(\tau)$ of the spin probes MeFASL $(10,3)$ (A) and MeFASL $(2,11)$ (B) for ULVs composed of PS/SM (2.4:1) with no(control) and in the presence of the different flavonoids (15 mM; as indicated) (Abram et al., 2013). 
172 | Ulrih et al.
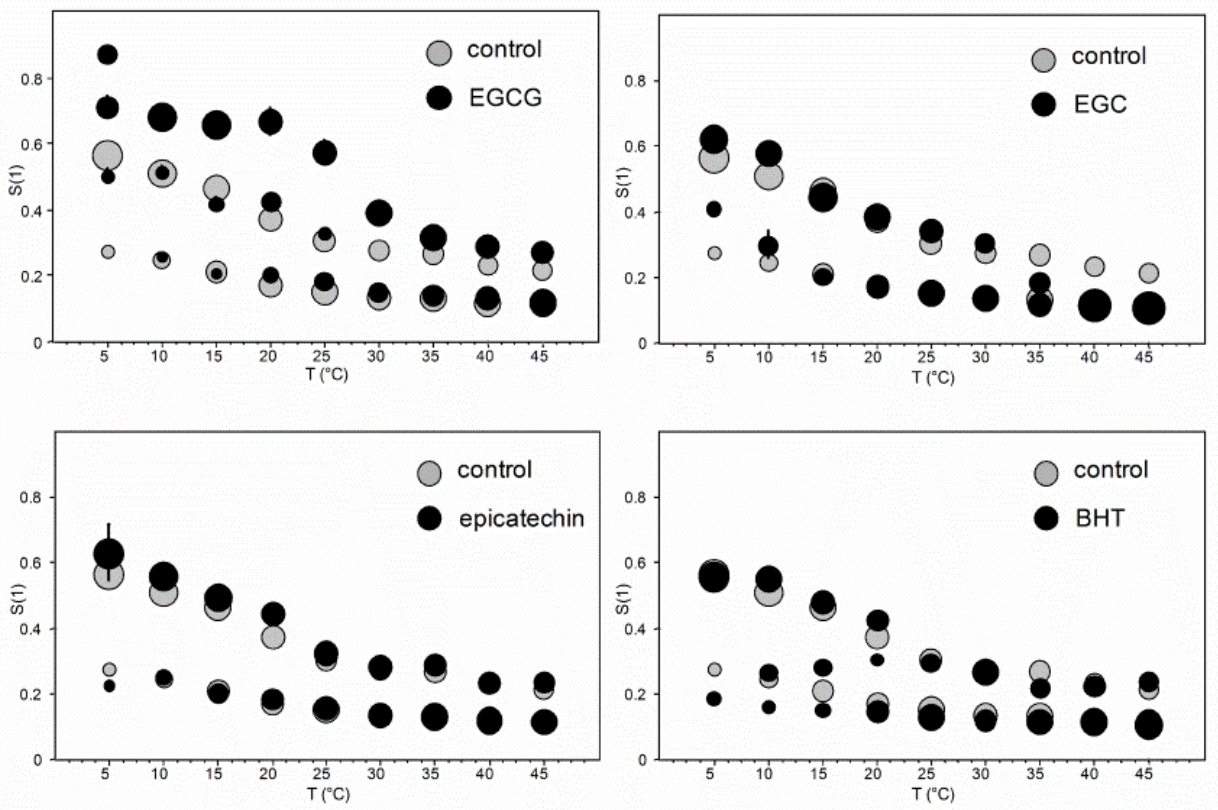

Figure 8: Temperature dependence of the order parameters (S) of MeFASL(10,3) in different regions of the membranes of the PS/SM (2.4:1) ULVs, as obtained as the best fits of the experimental spectra for the different phenolics (black) in comparison with the control (grey). The symbol size represents the proportion of the spin probe in the different membrane regions (Abram et al., 2013).

A

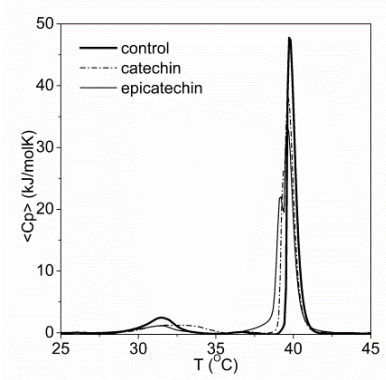

B

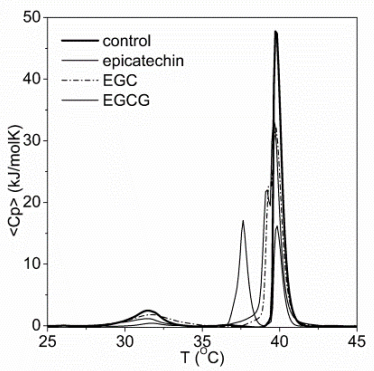

C

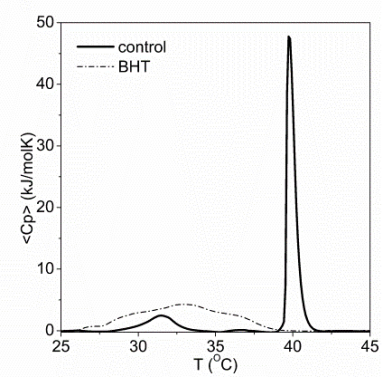

Figure 9: Differential scanning calorimetry thermograms of the DPPC vesicles (control) with the selected phenolics at the molar ratio of 1:1 at pH 7.0: (A) catechin and epicatechin; (B) epicatechin, epigallocatechin (EGC) and epigallocatechin-3-gallate (EGCG); and (C) butylated hydroxytoluene (BHT) (Abram et al., 2013). 
polyphenol, and it has numerous health benefits according to in-vivo studies. It is considered to be a potential artificial antioxidant or antimicrobial agent, although its use is often limited due to its degradation under conditions encountered during food processing and storage (Istenic, Korosec, \& Ulrih, 2016). For this reason, EGCG has been encapsulated in liposomes using the proliposome method (Perrett, Golding, \& Williams, 1991). The size of the liposomes was estimated at $1 \mu \mathrm{m}$ to $2 \mu \mathrm{m}$. These liposomes were further mixed with alginate and chitosan solutions, and microparticles were prepared using an encapsulator based on nozzle technology.

The encapsulation efficiency for the EGCG encapsulated into the alginate and chitosan microparticles was $0.83 \pm 0.05$ and $0.91 \pm 0.03 \%$ respectively (Fig. 10A and 10B). The porous matrices of the alginate and chitosan microparticles and the good water solubility of EGCG contributed to the high diffusion of the EGCG from the microparticles during the particle formation process. The encapsulation efficiency of the EGCG into the liposomes was $97.5 \pm 0.4 \%$. When the EGCG-loaded liposomes were further encapsulated within the alginate and chitosan microparticles (Fig. 10C and 10D), the encapsulation efficiencies were $97.3 \pm 0.3$ and $98.7 \pm 0.1 \%$ respectively. These data suggest that the EGCGloaded liposomes retain their stability during the microparticle preparation process. The encapsulation efficiency for chitosan microparticles containing liposomes is higher than that for liposomes alone, since the presence of liposomes contributed to lower porosity of the microparticles and, in turn, a portion of non-encapsulated EGCG from the liposome suspension was additionally entrapped within the chitosan matrix (Istenic et al., 2016). The interactions between EGCG and the compounds in these microparticles were proved by Fourier transform infrared spectroscopy and DSC.

Based on these investigations, we can conclude that EGCG was successfully encapsulated within the liposomes and within the alginate and chitosan microparticles reinforced with liposomes. All three of these systems showed gradual release of EGCG and promoted the stability of EGCG in alkaline medium and in fruit nectar. The major interactions here occurred between the lipo- somes and EGCG, and the interactions were not disrupted after incorporation of the alginate and chitosan matrices in the EGCG-loaded liposomes (Istenic et al., 2016).

\subsection{Stilbenes}

\section{Effects of resveratrol on membrane fluidity and encapsulation of resveratrol}

Resveratrol is a stilbene (C6-C2-C6) that is found in grapes, peanuts, berries, and cocoa beans, and hence also in red wine and chocolate. Research on stilbenes has focussed almost exclusively on trans-resveratrol, with the literature dominated by reports on the bioactivity of this aglycone at pharmacological rather than physiological concentrations (Rodriguez-Mateos et al., 2014). On the other hand, resveratrol is poorly soluble in water, and its bioavailability is poor, being characterised by weak absorption after oral administration and rapid metabolism in-vivo.

To overcome some of these drawbacks, the interactions of resveratrol with membranes were investigated, to determine whether these liposomes could be used as a delivery system for resveratrol. MLVs were prepared with the commercial P90NG lipid mixture using two methods: a thinfilm method (Lasch, Weissig, \& Brandl, 2003) and a proliposome method (Perrett et al., 1991), with the location of resveratrol in the liposomal membranes investigated using fluorescence spectroscopy, EPR spectroscopy and DSC (Balanc et al., 2015). To determine the relative benefits of the incorporation of resveratrol into phospholipid bilayers, the dose-dependency and timedependency of the oxidation kinetics of encapsulated resveratrol were determined based on the BODIPY 581/591 $\mathrm{C}_{11}$ fluorochrome, a lipophilic fluorescent fatty acid analogue.

The liposomes prepared by each of the methods indicated above showed the same behaviour, as demonstrated by fluorescence spectroscopy and EPR spectroscopy. According to the EPR spectroscopy measurements, the presence of resveratrol was confirmed to be in the inner part of the bilayer throughout the temperature range, 

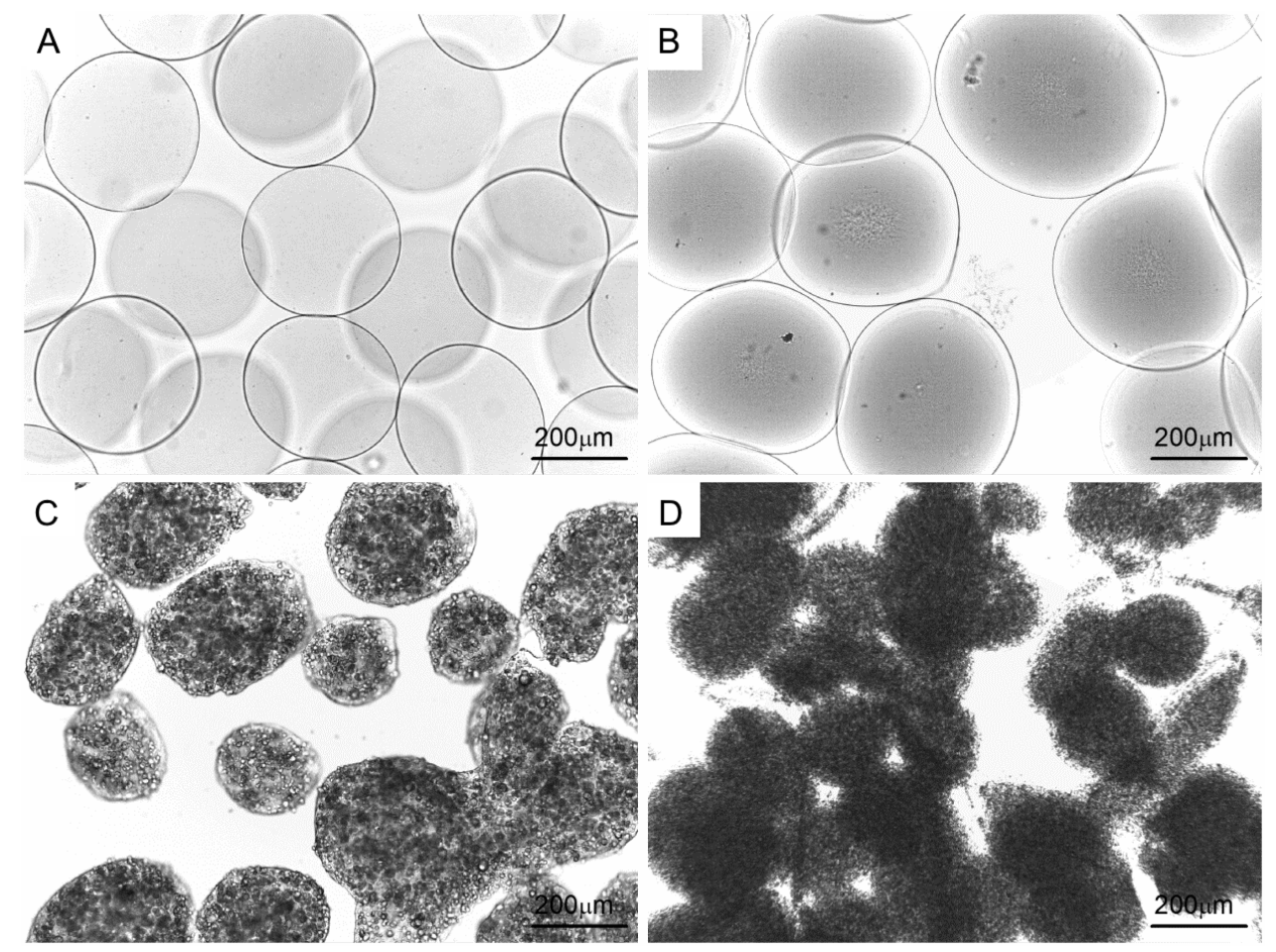

Figure 10: Representative light microscopy images of alginate microparticles (A), chitosan microparticles (B), and alginate microparticles (C) and chitosan microparticles (D) reinforced with liposomes, in aqueous solution at $\mathrm{pH} 5.5$, at $25{ }^{\circ} \mathrm{C}$ (from Istenic, Korosec, and Ulrih (2016).

with effects on the outer part of the membrane only at lower temperatures. These data were confirmed by the fluorescence spectroscopy using the two fluorophores indicated above: DPH to detect changes in the membrane fluidity in the middle of the bilayer, and TMA-DPH to detect changes in the membrane fluidity closer to the membrane surface. The presence of resveratrol made the membranes less fluid, which indicated that resveratrol increased the lipid ordering. By acting as a radical scavenger, resveratrol can protect liposomes made of this commercial mixture of lipids (Fig. 11) from lipid peroxidation, and can efficiently inhibit the production of $\mathrm{OH}$ radicals (Balanc et al., 2015).

\section{Conclusions}

The changes in lipid membrane fluidity promoted by the nine phenolics considered here correlate well with their total polar surface area and the number of H-bonds that each one can form. Some changes in the structures of these compounds were manifested more clearly with fluorescence, like the difference in polarisation between $p$-coumaric acid and ferulic acid. Computer simulation of the EPR spectra indicated two or three different fluidity characteristics of the membranes. The results show that if a compound has a high TSPA and a high number of H-bonds, it cannot enter or pass through these membranes by passive diffusion. In this case, it can bind to the hydrophilic surface of bilayers, as for EGCG, and promote changes in membrane fluidity. Encapsulation of EGCG within liposomes can be performed successfully, and within liposomes reinforced with alginate and chitosan microparticles. The presence of resveratrol in the inner part of the bilayer after its encapsulation in the phospholipid bilayer of a lipophilic fluorescent fatty acid analogue was confirmed. 
Polyphenolics and model lipid membranes | 175

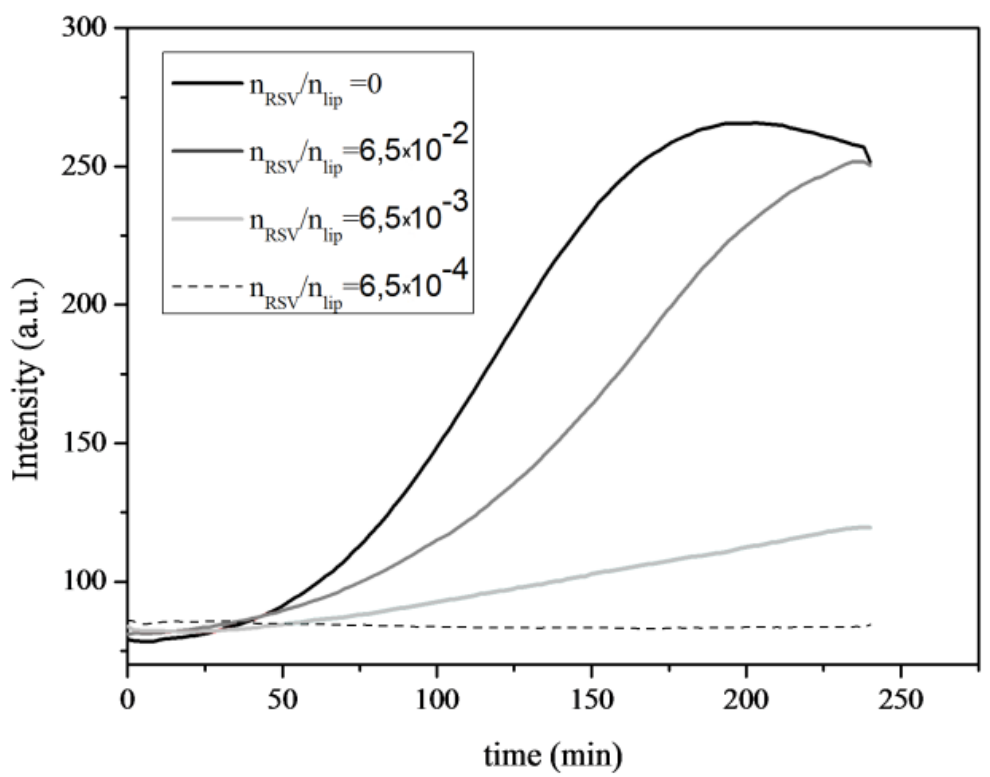

Figure 11: Effects of resveratrol at different molar ratios (as indicated) on the oxidation kinetics of BODIPY 581/591 $\mathrm{C}_{11}$, a fluorescent fatty acid analogue that acts as a lipophilic probe (from Balanc et al. (2015)).

These membranes became less fluid, and resveratrol protected the liposomes from lipid peroxidation.

\section{Acknowledgements}

The authors would like to express their gratitude for financial support from the Slovenian Research Agency, through the P4-0121 Research Programme.

\section{References}

Abram, V., Berlec, B., Ota, A., Sentjurc, M., Blatnik, P., \& Ulrih, N. P. (2013). Effect of flavonoid structure on the fluidity of model lipid membranes. Food Chemistry, 139(14), 804-813. doi:10.1016/j.foodchem.2013. 01.100
Balanc, B. D., Ota, A., Djordjevic, V. B., Sentjurc, M., Nedovic, V. A., Bugarski, B. M., \& Ulrih, N. P. (2015). Resveratrol-loaded liposomes: interaction of resveratrol with phospholipids. European Journal of Lipid Science and Technology, 117(10), 16151626. doi:10.1002/ejlt.201400481

Barthelmebs, L., Divies, C., \& Cavin, J. F. (2000). Knockout of the p-coumarate decarboxylase gene from lactobacillus plantarum reveals the existence of two other inducible enzymatic activities involved in phenolic acid metabolism. Applied and Environmental Microbiology, 66(8), 33683375. doi:10.1128/AEM.66.8.3368-3375. 2000

Bornsek, S. M., Ziberna, L., Polak, T., Vanzo, A., Ulrih, N. P., Abram, V., ... Passamonti, S. (2012). Bilberry and blueberry anthocyanins act as powerful intracellular antioxidants in mammalian cells. Food Chem- 
istry, 134(4), 1878-1884. doi:10.1016/j . foodchem.2012.03.092

Burt, S. (2004). Essential oils: their antibacterial properties and potential applications in foods - a review. International Journal of Food Microbiology, 94(3), 223-253. doi:10. 1016/j.ijfoodmicro.2004.03.022

Cheng, J.-C., Dai, F., Zhou, B., Yang, L., \& Liu, Z.-L. (2007). Antioxidant activity of hydroxycinnamic acid derivatives in human low density lipoprotein: mechanism and structure-activity relationship. Food Chemistry, 104 (1), 132-139. doi:10 . 1016 / j . foodchem.2006.11.012

Cowan, M. M. (1999). Plant products as antimicrobial agents. Clinical Microbiology Reviews, $12(4), 564-582$.

Dixon, R. A., Dey, P. M., \& Lamb, C. J. (1983). Phytoalexins - enzymology and molecularbiology. Advances In Enzymology And Related Areas Of Molecular Biology, 55, 1136.

Fraga, C. G. \& Oteiza, P. I. (2011). Dietary flavonoids: role of (-)-epicatechin and related procyanidins in cell signaling. Free Radical Biology and Medicine, 51(4), 813823. doi:10.1016/j.freeradbiomed.2011.06. 002

Gumul, D. \& Korus, J. (2006). Polyphenol content and antioxidant activity of rye bran extrudates produced at varying parameters of extrusion process. Food Science and Technology, 9(4), 1-11. Retrieved from http : / / www . ejpau . media.pl / volume9 / issue 4/art-11.html

Istenic, K., Korosec, R. C., \& Ulrih, N. P. (2016). Encapsulation of (-)-epigallocatechin gallate into liposomes and into alginate or chitosan microparticles reinforced with liposomes. Journal of the Science of Food and Agriculture, 96(13), 4623-4632. doi:10. $1002 /$ jsfa.7691

Kadoma, Y. \& Fujisawa, S. (2008). A comparative study of the radical-scavenging activity of the phenolcarboxylic acids caffeic acid, p-coumaric acid, chlorogenic acid and ferulic acid, with or without 2mercaptoethanol, a thiol, using the induction period method. Molecules, 13(10), 2488-2499. doi:10.3390/molecules13102488
Kier, A. B. (1990). Membrane-properties of metastatic and nonmetastatic cells cultured from C3h mice injected with Lm fibroblasts. Biochimica Et Biophysica Acta, 1022(3), 365-372. doi:10 . 1016 / 0005 2736(90)90287-X

Lakowicz, J. R. (2006). Principles of fluorescence spectroscopy. Springer Science \& Business Media. doi:10.1007/978-0-387-46312-4

Laranjinha, J. (2001). Caffeic acid and related antioxidant compounds: biochemical and cellular effect. In Handbook of antioxidants (2nd ed. Cadenas E., Packer L., pp. 279-302). CRC Press. doi:10.1201/ 9780203904046.pt5

Lasch, J., Weissig, V., \& Brandl, M. (2003). Liposomes. In V. P. Torchilin (Ed.), (Chap. Preparation of liposomes, Vol. 2, pp. 3-30). Oxford University Press, Oxford. Retrieved from https://global.oup. com / academic / product / liposomes - a practical - approach - $9780199636549 ? \mathrm{cc}=$ pt $\% 5$ C\&lang $=$ en $\% 5 C \& \#$

Lasic, D. D. (1993). Liposomes: from physics to applications. Elsevier.

Manach, C., Scalbert, A., Morand, C., Remesy, C., \& Jimenez, L. (2004). Polyphenols: food sources and bioavailability. American Journal of Clinical Nutrition, 79(5), 727-747.

Mui, B. \& Hope, M. J. (2006). Formation of large unilamellar vesicles by extrusion. In Liposome technology, volume $i$ (pp. 5565). Informa Healthcare. doi:10 . $1201 /$ 9780849397264.ch4

Ota, A., Abramovic, H., Abram, V., \& Ulrih, N. P. (2011). Interactions of p-coumaric, caffeic and ferulic acids and their styrenes with model lipid membranes. Food Chemistry, 125(4), 1256-1261. doi:10.1016/j . foodchem.2010.10.054

Perrett, S., Golding, M., \& Williams, W. P. (1991). A simple method for the preparation of liposomes for pharmaceutical applications - characterization of the liposomes. Journal of Pharmacy and Pharmacology, 43(3), 154-161.

PubChem. (2010). PubChem Compound. Retrieved May 9, 2010. Retrieved from http: //pubchem.ncbi.nlm.nih.gov/compound/ 
PubChem. (2017). PubChem Compound. Retrieved April 24, 2017. Retrieved from http: //pubchem.ncbi.nlm.nih.gov/compound/

Riske, K. A., Barroso, R. P., Vequi-Suplicy, C. C., Germano, R., Henriques, V. B., \& Lamy, M. T. (2009). Lipid bilayer pretransition as the beginning of the melting process. Biochimica Et Biophysica Actabiomembranes, 1788(5), 954-963. doi:10 . 1016/j.bbamem.2009.01.007

Rodriguez-Mateos, A., Vauzour, D., Krueger, C. G., Shanmuganayagam, D., Reed, J., Calani, L., .. . Crozier, A. (2014). Bioavailability, bioactivity and impact on health of dietary flavonoids and related compounds: an update. Archives of Toxicology, 88(10), 1803-1853. doi:10.1007/s00204-014-1330-7

Rosazza, J. P. N., Huang, Z., Dostal, L., Volm, T., \& Rousseau, B. (1995). Review: biocatalytic transformations of ferulic acid: an abundant aromatic natural product. Journal of Industrial Microbiology, 15(6), 457471. doi:10.1007/BF01570016

Selvaraj, S., Krishnaswamy, S., Devashya, V., Sethuraman, S., \& Krishnan, U. M. (2015). Influence of membrane lipid composition on flavonoid-membrane interactions: implications on their biological activity. Progress in Lipid Research, 58, 1-13. doi:10.1016/j. plipres.2014.11.002

Šentjurc, M., Štrancar, J., \& Koklič, T. (2002). Membrane domain alteration under the action of biologically active substances: an epr study. Current Topics in Biophysics. Retrieved from http:// www.wbc. poznan . $\mathrm{pl} /$ dlibra $/$ docmetadata? id $=102871 \% 5 \mathrm{C} \&$ from $=\% 5 \mathrm{C} \&$ dirids $=1 \% 5 \mathrm{C} \&$ ver_id $=\% 5 \mathrm{C} \&$ $\mathrm{lp}=2 \% 5 \mathrm{C} \& \mathrm{QI}=$

Šentjurc, M., Vrhovnik, K., \& Kristl, J. (1999). Liposomes as a topical delivery system: the role of size on transport studied by the epr imaging method. Journal of Controlled Release, 59(1), 87-97. doi:10 . 1016 / S01683659(98)00181-3

Strancar, J., Koklic, T., \& Arsov, Z. (2003). Soft picture of lateral heterogeneity in biomembranes. Journal of Membrane Biology, 196(2), 135-146. doi:10.1007/s00232003-0633-z
Strancar, J., Koklic, T., Arsov, Z., Filipic, B., Stopar, D., \& Hemminga, M. A. (2005). Spin label epr-based characterization of biosystem complexity. Journal of Chemical Information and Modeling, 45 (2), 394-406.

Subczynski, W. K., Wisniewska, A., Yin, J. J., Hyde, J. S., \& Kusumi, A. (1994). Hydrophobic barriers of lipid bilayermembranes formed by reduction of water penetration by alkyl chain unsaturation and cholesterol. Biochemistry, 33(24), 7670-7681. doi:10.1021/bi00190a022

Surh, Y. J. (2003). Cancer chemoprevention with dietary phytochemicals. Nature Reviews Cancer, 3(10), 768-780. doi:10.1038/ nrc1189

Terao, J. (2009). Dietary flavonoids as antioxidants. In T. Yoshikawa (Ed.), Food factors for health promotion (Vol. 61, pp. 87-94). Forum of Nutrition. doi:10.1159/000212741

Ulrih, N. P., Ota, A., Sentjurc, M., Kure, S., \& Abram, V. (2010). Flavonoids and cell membrane fluidity. Food Chemistry, 121(1), 78-84. doi:10.1016/j. foodchem . 2009.12.006

Verstraeten, S. V., Fraga, C. G., \& Oteiza, P. I. (2015). Interactions of flavan-3-ols and procyanidins with membranes: mechanisms and the physiological relevance. Food and Function, 6(1), 32-40.

Xu, X. \& London, E. (2000). The effect of sterol structure on membrane lipid domains reveals how cholesterol can induce lipid domain formation. Biochemistry, 39(5), 843849.

Ziberna, L., Kim, J.-H., Auger, C., Passamonti, S., \& Schini-Kerth, V. (2013). Role of endothelial cell membrane transport in red wine polyphenols-induced coronary vasorelaxation: involvement of bilitranslocase. Food and Function, 4 (10), 1452-1456. 